\title{
The efficacy of vitamin C, thiamine, and corticosteroid therapy in adult sepsis patients: a systematic review and meta-analysis
}

\author{
Manoj Kumar Reddy Somagutta', Maria Kezia Lourdes Pormento', Muhammad Adnan Khan', \\ Alaa Hamdan', Namrata Hange', Manish KC', Sukrut Pagad', Molly Sanjay Jain'2, Sivasthikka Lingarajah ${ }^{3}$, \\ Vishal Sharma ${ }^{3}$, Jaspreet Kaur ${ }^{4}$, Bernard Emuze ${ }^{2}$, Erkan Batti ${ }^{5}$, Obumneme Jude lloeje ${ }^{6}$ \\ ${ }^{1}$ Department of Clinical and Translational Research, Larkin Community Hospital, South Miami, FL, ${ }^{2}$ Department of Medicine, Saint James School of \\ Medicine, Park Ridge, IL; ${ }^{3}$ Department of Medicine, Windsor University School of Medicine, Cayon, St. Kitts and Nevis, USA; ${ }^{4}$ Department of Medicine, \\ Medical University of Silesia, Katowice, Poland; ${ }^{5}$ Department of Medicine, Washington University of Health and Science, San Pedro, Belize; \\ ${ }^{6}$ Department of Medicine, University of Health Sciences, Antigua, Antigua and Barbuda
}

Previous studies have suggested favorable outcomes of hydrocortisone, ascorbic acid (vitamin C), and thiamine (HAT) therapy in patients with sepsis. However, similar results have not been duplicated in sequential studies. This meta-analysis aimed to reevaluate the value of HAT treatment in patients with sepsis. Electronic databases were searched up until October 2020 for any studies that compared the effect of HAT versus non-HAT use in patients with sepsis. Data from 15 studies (eight randomized controlled trials [RCTs] and seven cohort studies) involving 67,349 patients were included. The results from the RCTs show no significant benefit of triple therapy on hospital mortality (risk ratio $[R R], 0.99 ; P=0.92 ; I^{2}=0 \%$ ); intensive care unit (ICU) mortality $\left(R R, 0.77 ; P=0.20 ; I^{2}=58 \%\right)$; ICU length of stay (weighted mean difference [WMD], $0.11 ; P=0.86 ; I^{2}=37 \%$ ) or hospital length of stay (WMD: $\left.0.57 ; P=0.49 ; I^{2}=17 \%\right)$, and renal replacement therapy $\left(R R, 0.64 ; P=0.44 ; I^{2}=39 \%\right)$. The delta Sequential Organ Failure Assessment (SOFA) score favored treatment after a sensitivity analysis (WMD, $-0.72 ; \mathrm{P}=0.01$; $I^{2}=32 \%$ ). However, a significant effect was noted for the duration of vasopressor use (WMD, $\left.-25.49 ; \mathrm{P}<0.001 ; I^{2}=46 \%\right)$. The results from cohort studies have also shown no significant benefit of HAT therapy on hospital mortality, ICU mortality, ICU length of stay, length of hospital stay, the delta SOFA score, the use of renal replacement therapy, or vasopressor duration. HAT therapy significantly reduced the duration of vasopressor use and improved the SOFA score but appeared not to have significant benefits in other outcomes for patients with sepsis. Further RCTs can help understand its benefit exclusively.

Key Words: ascorbic acid; septic shock; steroids; thiamine; thiamine therapy; vitamin C

\section{INTRODUCTION}

Globally, sepsis is a life-threatening organ dysfunction that affects millions of patients every year due to a dysregulated host response to infection. The underlying circulatory and cellular/metabolic abnormalities are profound enough to substantially increase patient mortality.

\section{Review Article}

Received: January 24, 2021

Revised: May 2, 2021

Accepted: May 4, 2021

Corresponding author Manoj Kumar Reddy Somagutta Department of Clinical and Translational Research, Larkin Community Hospital, 7031 SW 62nd Ave, South Miami, FL 33143, USA

Tel: +1-773-289-2848

Fax: +1-773-289-2848

E-mail:manojleo.go@gmail.com

Copyright () 2021 The Korean Society of Critical Care Medicine

This is an Open Access article distributed under the terms of Creative Attributions Non-Commercial License (https:// creativecommons.org/li-censes/by-nc/4.0/) which permits unrestricted noncommercial use, distribution, and reproduction in any medium, provided the original work is properly cited. 
Organ dysfunction is measured as an acute change in the total Sequential Organ Failure Assessment (SOFA) score of 2 points or more due to an infectious cause. Septic shock is characterized by persevering hypotension that obligates vasopressors to maintain a mean arterial pressure of $65 \mathrm{~mm} \mathrm{Hg}$ or greater and a serum lactate level $>2 \mathrm{mmol} / \mathrm{L}(18 \mathrm{mg} / \mathrm{dl})$ despite adequate volume resuscitation [1-4]. By 2017, 48.9 million cases and 11 million sepsis-related deaths had been reported globally [5]. Early recognition, appropriate anti-infective agents, source control, and a physiological approach to fluid management to maintain hemodynamic stability have remained the cornerstones of sepsis therapy [6].

Ascorbic acid has bacteriostatic activity via oxidative-stressmediated cell damage. It acts as an antioxidant by scavenging free radicals Immunity stimulator to restore deficits, regulate macrophage function, and reduce inflammatory mediators. Its contribution to endothelial cell proliferation and apoptosis, smooth muscle-mediated vasodilatation, and endothelial barrier permeability render ascorbic acid an essential agent in treating the pathophysiological changes of septic shock that have anti-inflammatory and antioxidant properties [7-13].

Thiamine has proved to be appealing adjunctive therapy and a metabolic resuscitator for patients with septic shock $[14,15]$. Thiamine levels are depleted during critical illness, which contributes to mitochondrial metabolic impairments and causes lactic acidosis; replenishing thiamine during critical illness might improve organ dysfunction through increased lactate clearance [15-18]. Corticosteroids are thought to modulate several immune effects, including a reduced inducible nitric oxide formation in septic shock patients through dysregulation of the hypothalamic-pituitary-adrenal axis [19-21].

The Surviving Sepsis Campaign Guidelines have recommended that adding extra low-dose corticosteroids in septic shock patients who are unresponsive to vasopressors resulted in an early reversal of septic shock, increased ventilator-free days, a reduced need for vasopressors, a shorter intensive care unit (ICU) length of stay (LOS), and potentially lower mortality [19-27]. Hydrocortisone has improved the survival and reversal rates of septic shock in patients with relative adrenal insufficiency [24-26]. The combination of hydrocortisone, ascorbic acid (vitamin C), and thiamine (HAT) is a promising new therapy for sepsis resuscitation [27-29]. Corticosteroids appear to have synergistic biological effects when combined with intravenous ascorbic acid and thiamine and may lead to improved patient-centered outcomes [29,30]. The overlapping anti-inflammatory properties of glucocorticoids and ascorbic acid reduce the production of proinflammatory mediators and re-

\section{KEY MESSAGES}

- Several studies have suggested favorable outcomes when using hydrocortisone, ascorbic acid (vitamin C), and thiamine (HAT) in patients with sepsis.

- A pooled analysis showed no significant benefit of HAT therapy on patient mortality or the length of hospital stay.

- A pooled analysis from the randomized controlled trials indicated that HAT therapy significantly reduced the duration of vasopressor use among sepsis patients and improved their Sequential Organ Failure Assessment scores.

active oxygen species (ROS) that are associated with endothelial injury, mitochondrial damage, and organ failure, which are all characteristic of sepsis. Thiamine possibly acts synergistically with glucocorticoids and ascorbic acid to limit mitochondrial oxidative injury and restore mitochondrial function and energy production [30]. This study will review the combined effects of HAT therapy in sepsis and its efficacy in mortality reduction, ICU LOS, the delta SOFA score, renal replacement therapy (RRT), and the duration of vasopressor use.

\section{MATERIALS AND METHODS}

\section{Data Sources and Search Strategy}

This systematic review and meta-analysis were performed following the preferred reporting items for systematic reviews and meta-analyses (PRISMA) guidelines. The Medline, PubMed, Clinicaltrials.gov, Embase, Web of Science, Cochrane, Google Scholar, Scopus, and CINAHL databases were searched from the genesis of the idea until October 2020. Another search was carried out prior to the submission of this paper to include newly published articles. The search for articles was done using the keywords "septic ascorbic acid," "vitamin C," "corticosteroids," "steroids," "thiamine," and "septic shock" and produced 384,629 results from all databases. We identified a total of 29 articles with the potential to be included in the study.

Institutional Review Board approval was waived for this study because it is a review of publicly available data. The systematic review protocol described here was accepted by PROSPERO, the international prospective registry of systematic reviews of the National Institute for Health Research (CRD42020209086).

\section{Study Selection}

All cohort studies (both prospective or retrospective) and RCTs 
that assessed the effectiveness of ascorbic acid, corticosteroids, and thiamine in patients with septic shock who had been admitted to the ICU were considered eligible for our study. Eligible studies compared ascorbic acid, corticosteroids, and thiamine with the standard of care, placebo, or no treatment. Five reviewers (AH, MKLP, NH, MSJ, and MKC) independently screened all articles and selected only those that strictly met the eligibility criteria. A sixth reviewer (MKRS) was consulted in case of disagreement. All the duplicates were removed during the first screening, followed by a second screening to remove articles that did not fulfill our inclusion/exclusion criteria, such as review articles, case-control studies, letters to the editor, non-human studies, and non-English literature.

\section{Data Extraction and Ascertainment of the Risk of Bias}

Five independent reviewers (AH, MKLP, NH, MSJ, and MKC) extracted data from the studies onto preestablished forms. The review authors independently used the specially designed forms to gather information on the study characteristics, number of participants, and demographic information about the patients. They were followed by tables comparing the delta SOFA score (72 hours), hospital mortality, ICU mortality, ICU LOS, hospital LOS, RRT for acute kidney injury, duration of vasopressor use, mechanical ventilation-free days, and procalcitonin clearance (72 hours).

Five reviewers independently determined the risk of bias qualitatively for the selection of the study groups, the comparability of the groups, and the ascertainment of the outcome of cohort studies using the Newcastle-Ottawa Scale checklist $[31,32]$. To assess the randomization process, deviations from the intended intervention, missing outcome data, measurement of the outcome, and selection of the reported result of RCTs were identified using the Risk of Bias Tool (ROB 2). Disagreements were resolved by discussion or with a sixth author. The results of the risk of bias are detailed in Supplementary Tables 1 and 2.

\section{Statistical Analysis}

Data were analyzed using Review Manager ver. 5.4 (Cochrane Collaboration; London, UK). Continuous variables were reported as the mean and standard deviation (SD), and dichotomous variables were reported as the frequency and proportion. Luo et al.'s [33] and Wan et al.'s [34] method was used to convert all values expressed as the median and interquartile range into the mean and SD. The results of continuous data are presented using the mean difference (MD), and dichotomous data are presented using risk ratios (RRs), both with a
95\% confidence interval (CI). Heterogeneity was evaluated using the $\mathrm{I}^{2}$ statistic, with $30 \%-50 \%$ indicating mild heterogeneity, 50\%-75\% suggesting moderate heterogeneity, and 75\%-100\% indicating high heterogeneity. A subgroup analysis was performed by age, and a sensitivity analysis was carried out to assess any outcomes with substantial or considerable heterogeneity. A sensitivity analysis was performed by removing each trial or cohort study and then reanalyzing the remaining studies. We employed a sequential algorithm for the sensitivity analysis in which one study was excluded from the calculations. The study that caused the largest decrease in $\mathrm{I}^{2}$ is then excluded from the calculations [35]. A pooled estimate of the MD was calculated using the Mantel-Haenszel randomeffects model to account for heterogeneity resulting in indifference from study design [36,37]. A RR with 95\% CIs and weighted mean differences (WMDs) with 95\% CIs were used. A Pvalue $<0.05$ was considered statistically significant.

\section{RESULTS}

\section{Search Results and Study Characteristics}

The initial search revealed 384,629 articles. After applying the eligibility criteria, 15 studies were selected for inclusion in the meta-analysis. The search revealed eight randomized controlled trials and seven cohort studies.

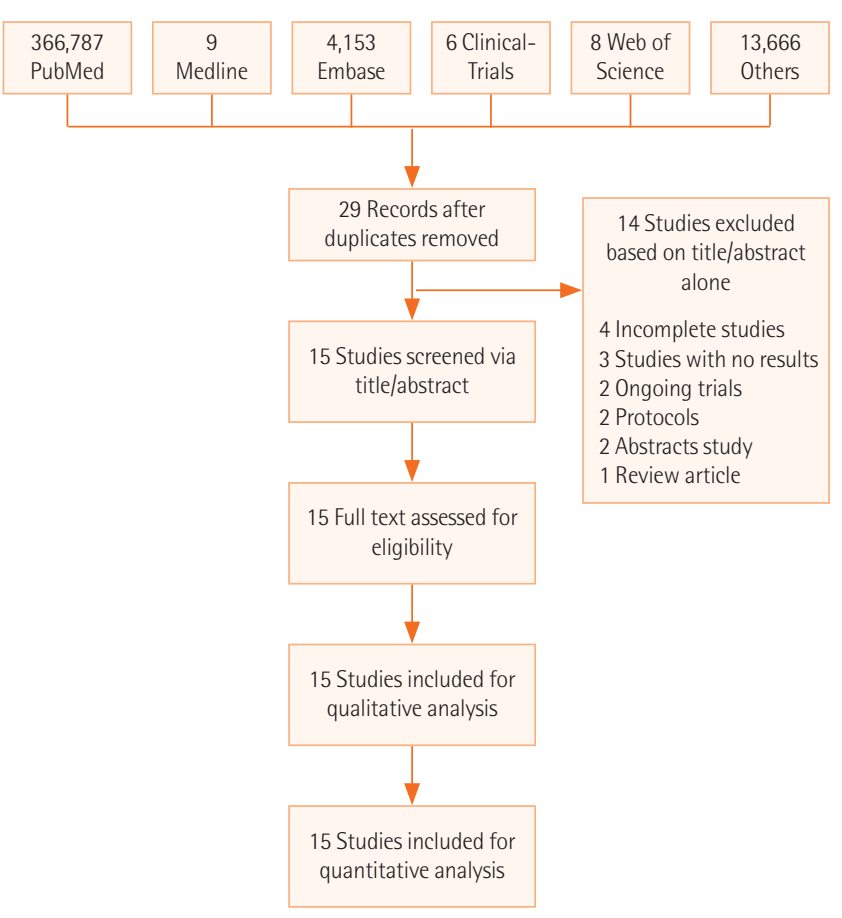

Figure 1. Preferred reporting items for systematic reviews and meta-analyses flow diagram. 


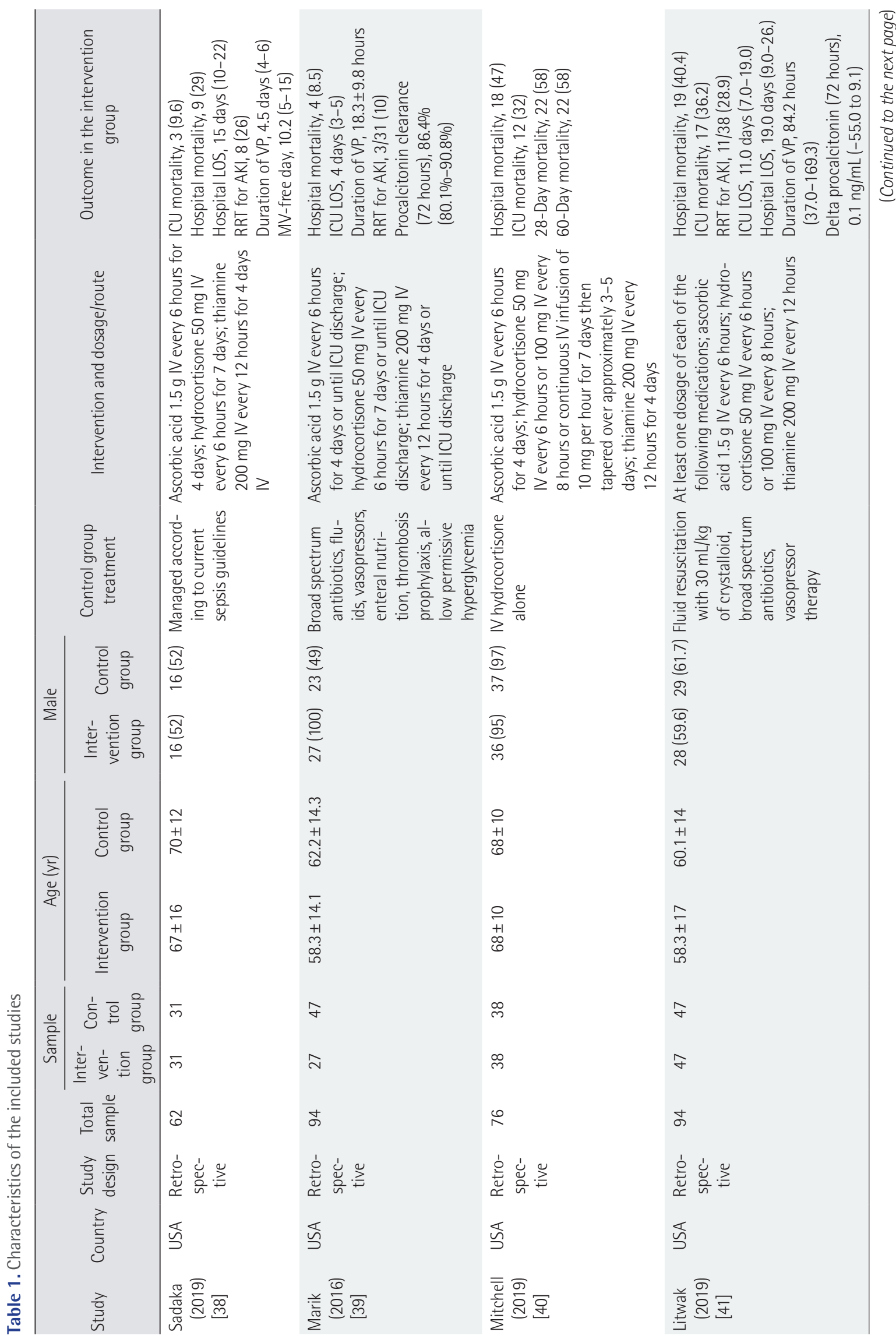




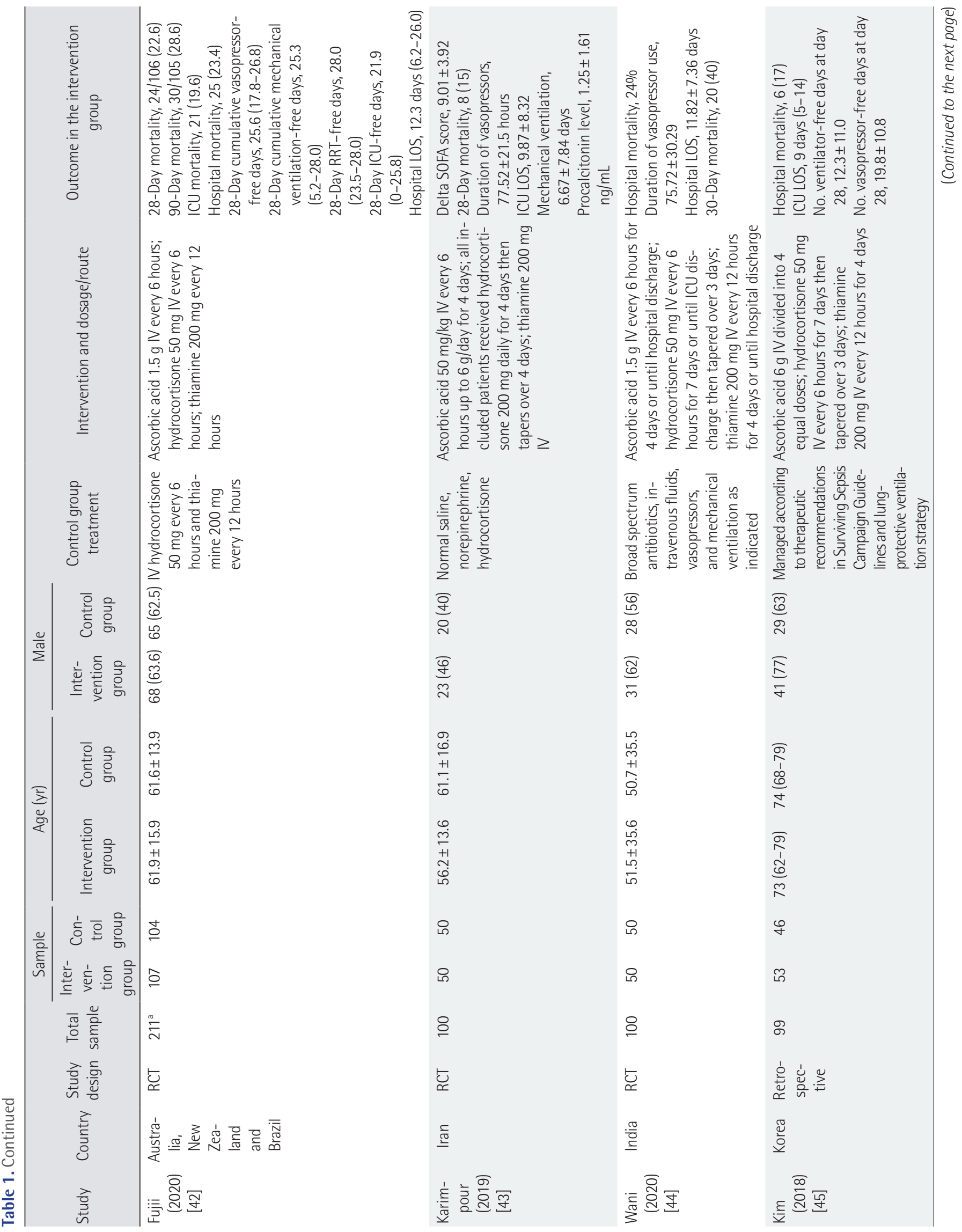




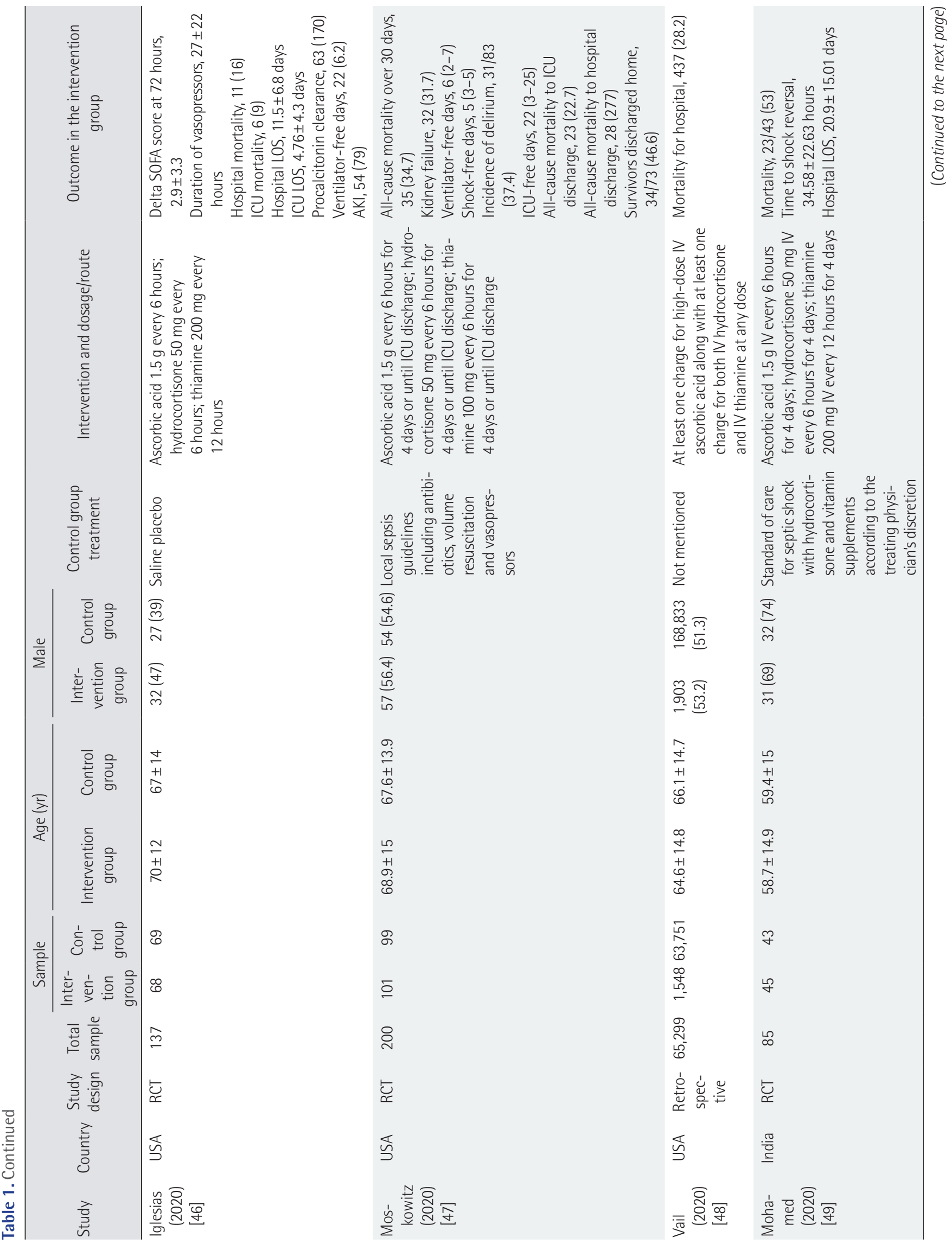




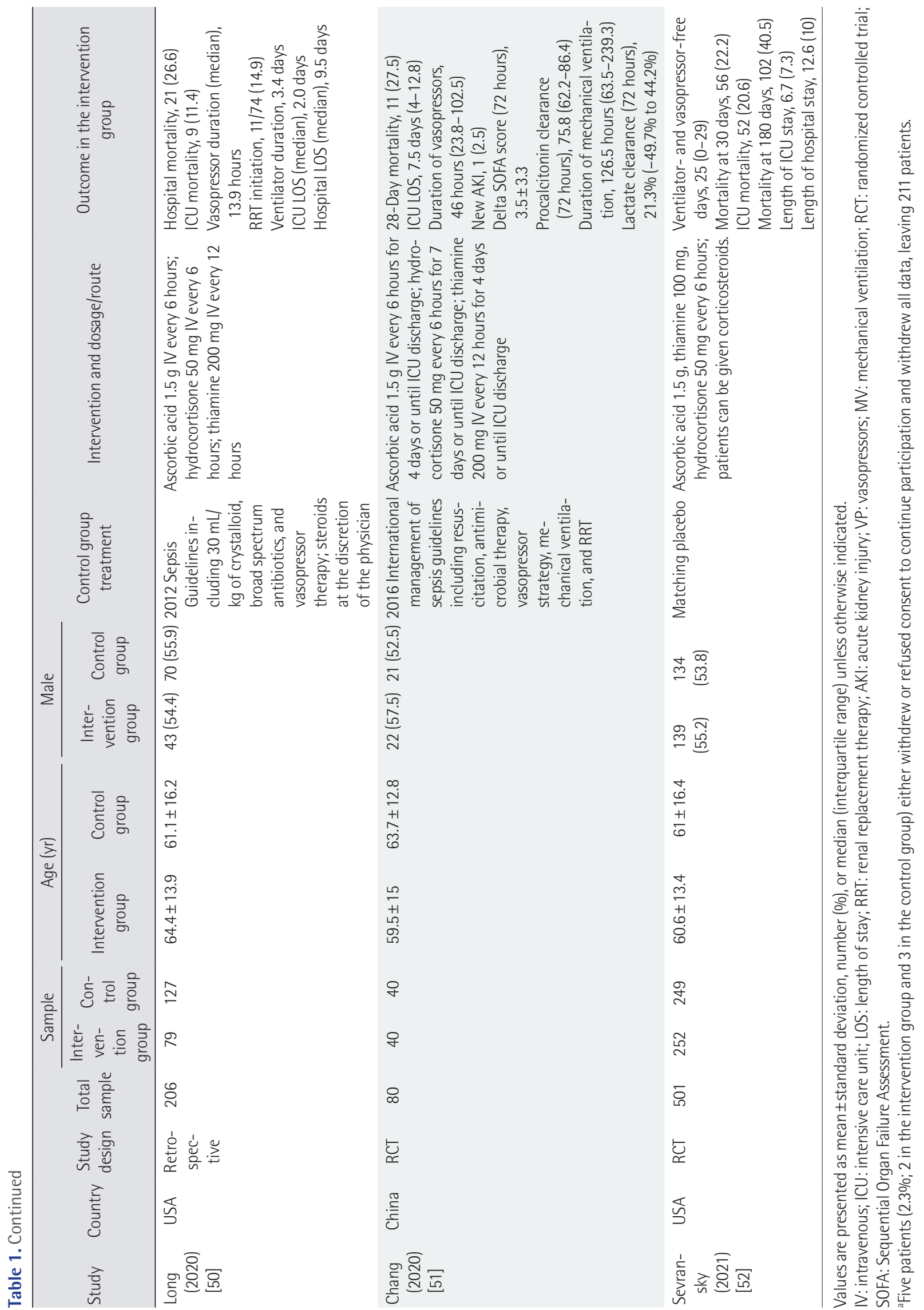




\section{PRISMA Flowchart}

The PRISMA flowchart (Figure 1) summarizes the literature search. Out of the 15 qualified studies with 67,349 total participants, 2,905 received HAT combination therapy. Eight RCTs with 1,419 patients and 7 retrospective cohort studies with 65,930 patients were included. The baseline characteristics of the included studies are detailed in Table 1 [38-52].

\section{Hospital Mortality}

In Figure 2, the results from the RCTs showed no significant benefit of HAT therapy on hospital mortality (RR, 0.99; 95\% CI, 0.83-1.18; $\mathrm{P}=0.92 ; \mathrm{I}^{2}=0 \%$ ). Pooled data from retrospective cohort studies showed similar results (RR, 0.78; 95\% CI, 0.52$\left.1.17 ; \mathrm{P}=0.23 ; \mathrm{I}^{2}=84 \%\right)$. A sensitivity analysis was performed, which showed that the exclusion of the study by Vail et al. [48] made the sample less heterogeneous $\left(\mathrm{I}^{2}=48 \%\right)$; however, there was still no significant benefit of HAT therapy on hospital mortality. A funnel plot revealed no publication bias among the included studies (Supplementary Figure 1).

\section{ICU Mortality}

The results from the RCTs and retrospective cohorts showed no significant benefit of HAT therapy on ICU mortality with an RR of 0.77 (95\% CI, 0.51-1.15; P=0.20; $\mathrm{I}^{2}=58 \%$ ) and an RR of 0.62 (95\% CI, 0.35-1.09; P =0.10; I²=61\%), respectively (Figure 3). A sensitivity analysis was performed, which showed that the exclusion of the study by Sadaka et al. [38] or Sevransky et al. [52] made the data less heterogeneous $\left(\mathrm{I}^{2}=43 \%\right)$; however, there was still no significant benefit of triple therapy on ICU mortality.

\section{ICU Length of Stay}

The results from the RCTs (WMD, $0.11 ; 95 \%$ CI, -1.06 to 1.28 ; $\left.\mathrm{P}=0.86 ; \mathrm{I}^{2}=37 \%\right)$ and retrospective studies (WMD, $-1.05 ; 95 \%$ CI, -2.83 to $0.73 ; \mathrm{P}=0.25 ; \mathrm{I}^{2}=46 \%$ ) showed no significant benefit of HAT therapy on the ICU LOS (Figure 4).

\section{Delta SOFA Score}

As shown in Figure 5, the results from the RCTs did not identify a significant benefit of HAT therapy on the delta SOFA score

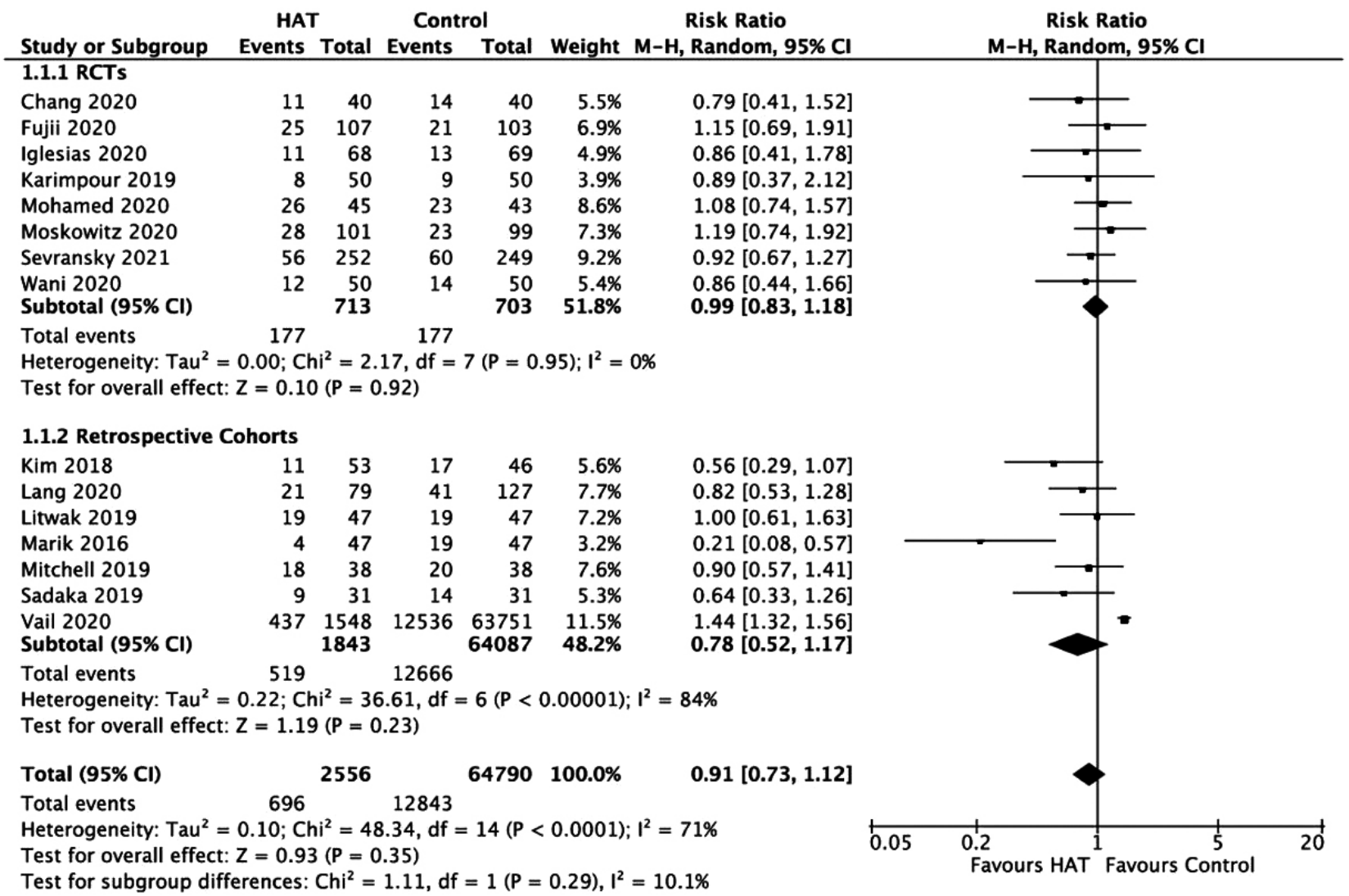

Figure 2. Forest plot showing results of triple therapy from randomized controlled trials (RCTs) and cohorts studies on the hospital mortality. HAT: hydrocortisone, ascorbic acid (vitamin C), and thiamine; Cl: confidence interval; df: degrees of freedom. 


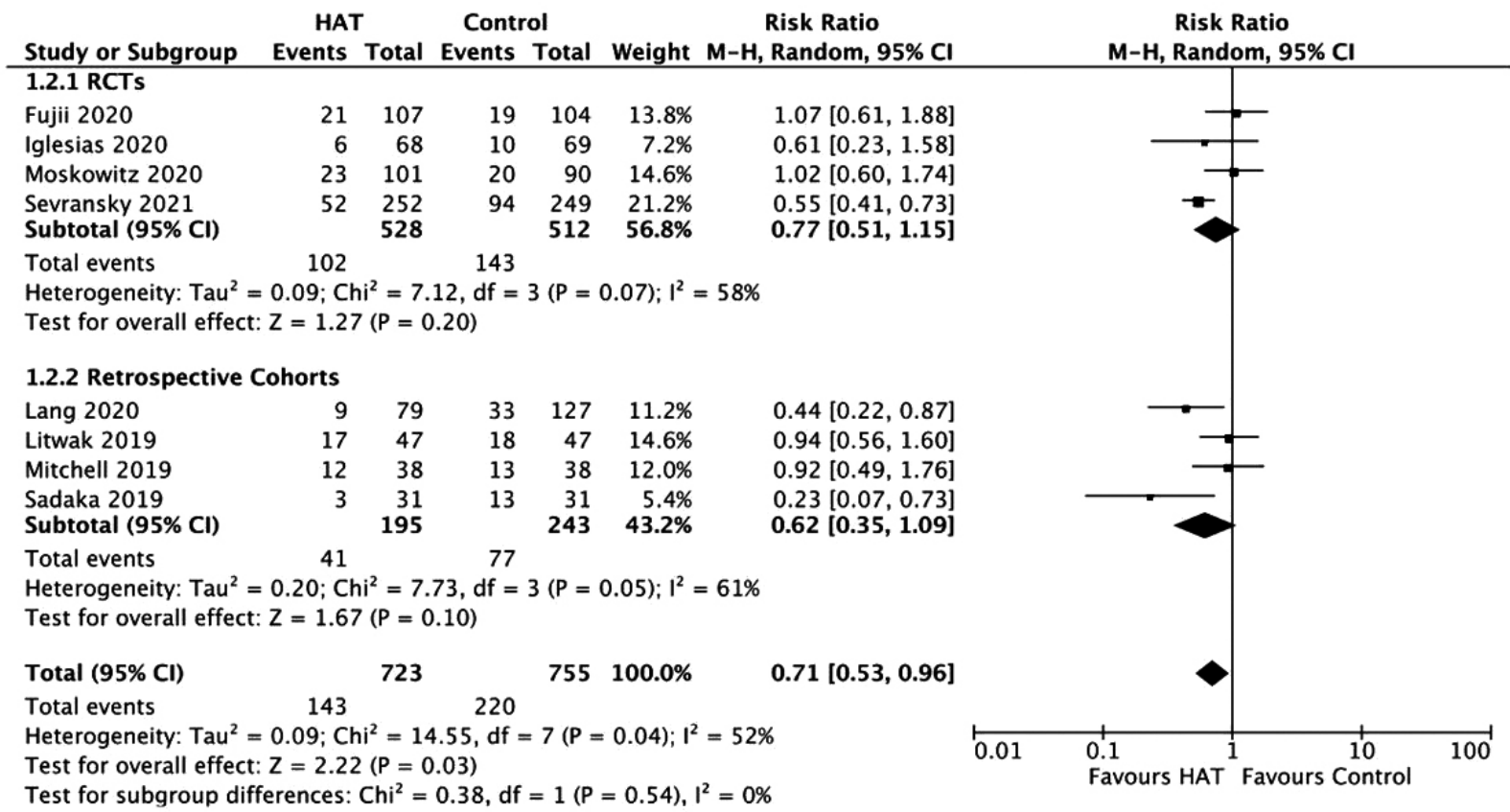

Figure 3. Forest plot showing results of triple therapy from randomized controlled trials (RCTs) and cohort studies on the intensive care unit. HAT: hydrocortisone, ascorbic acid (vitamin C), and thiamine; Cl: confidence interval; df: degrees of freedom.

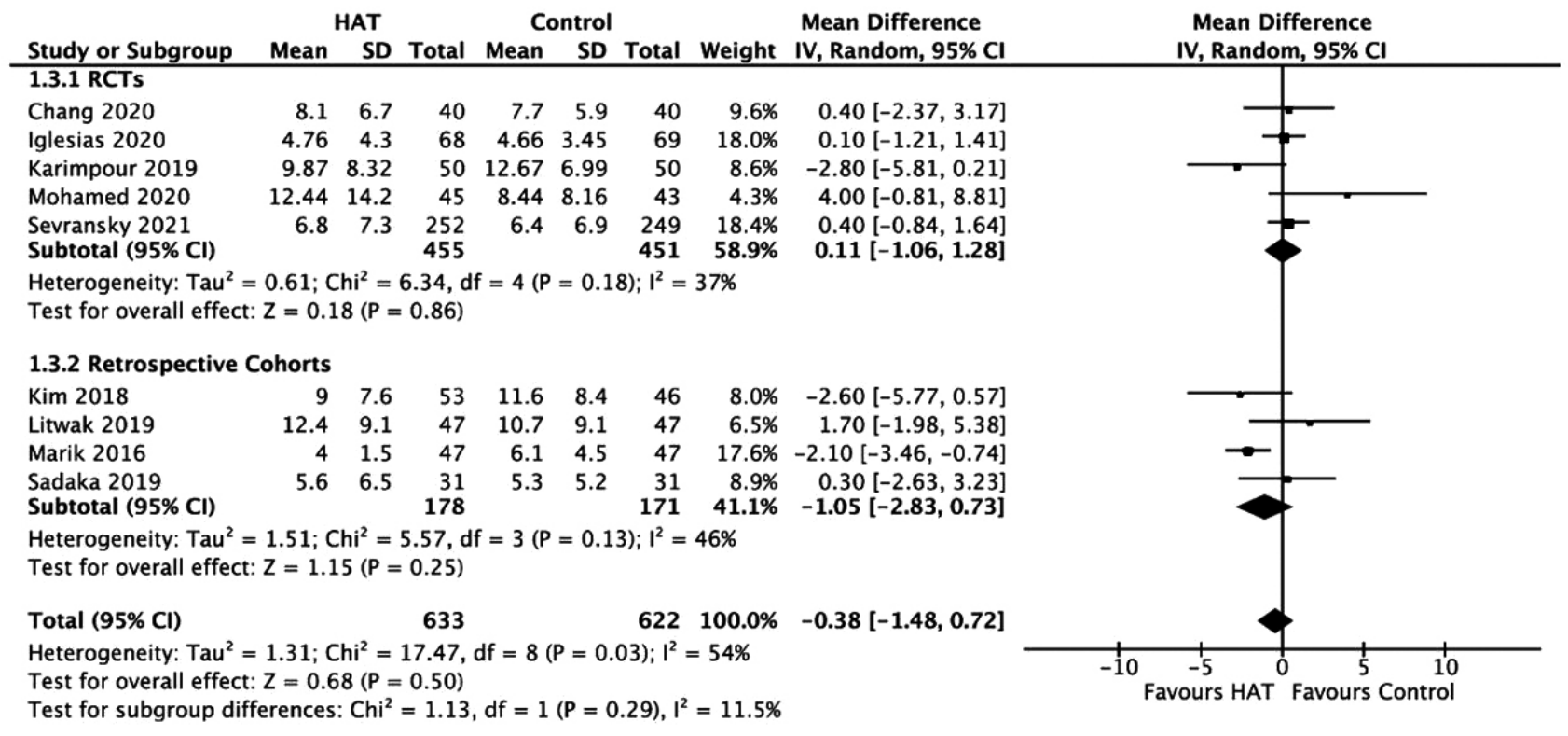

Figure 4. Forest plot showing results of triple therapy from randomized controlled trials (RCTs) and cohorts studies on the intensive care unit length of stay. HAT: hydrocortisone, ascorbic acid (vitamin C), and thiamine; SD: standard deviation; IV: weighted mean difference; Cl: confidence interval; df: degrees of freedom.

(WMD, $-0.42 ; 95 \%$ CI, -1.20 to $0.35 ; \mathrm{P}=0.29 ; \mathrm{I}^{2}=66 \%$ ). Similarly, the results from the retrospective cohorts showed no significant difference between groups (WMD, -1.73; 95\% CI, -4.34 to $0.88 ; \mathrm{P}=0.19 ; \mathrm{I}^{2}=91 \%$ ).

As a sensitivity analysis, the exclusion of the RCT study by Karimpour et al. [43] made the data homogenous $\left(\mathrm{I}^{2}=32 \%\right)$ and showed favor towards the treatment group. Similarly, the exclusion of the retrospective cohort study of Marik et al. [39] made the data homogenous $\left(\mathrm{I}^{2}=14 \%\right)$ but did not show any significant difference between the delta SOFA score of the treatment group and the control group. When we excluded both studies of Karimpour et al. [43] and Marik et al. [39], the 


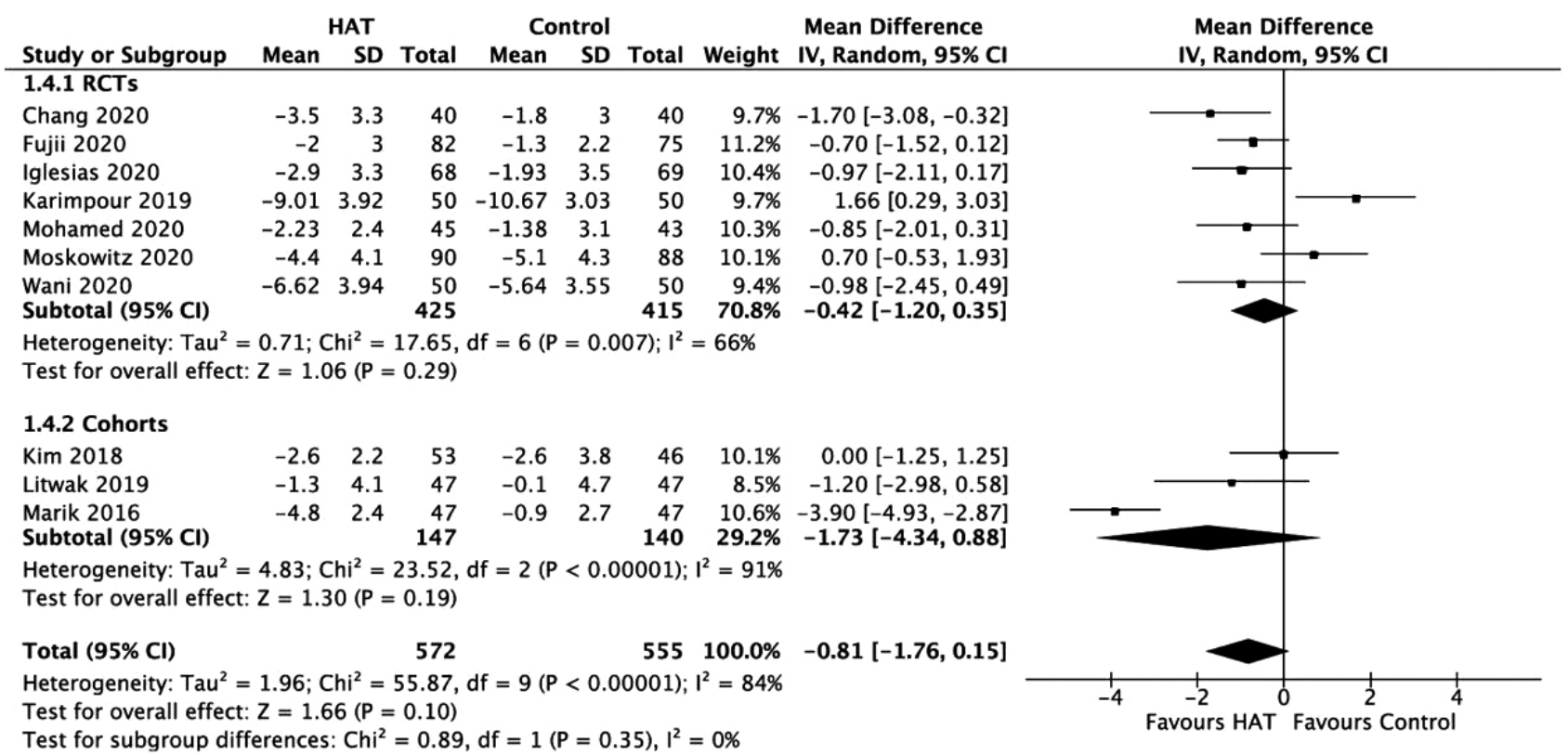

Figure 5. Forest plot showing results of triple therapy from randomized controlled trials (RCTs) and cohorts studies on delta Sequential Organ Failure Assessment (SOFA) score. HAT: hydrocortisone, ascorbic acid (vitamin C), and thiamine; SD: standard deviation; IV: weighted mean difference; $\mathrm{Cl}$ : confidence interval; df: degrees of freedom.

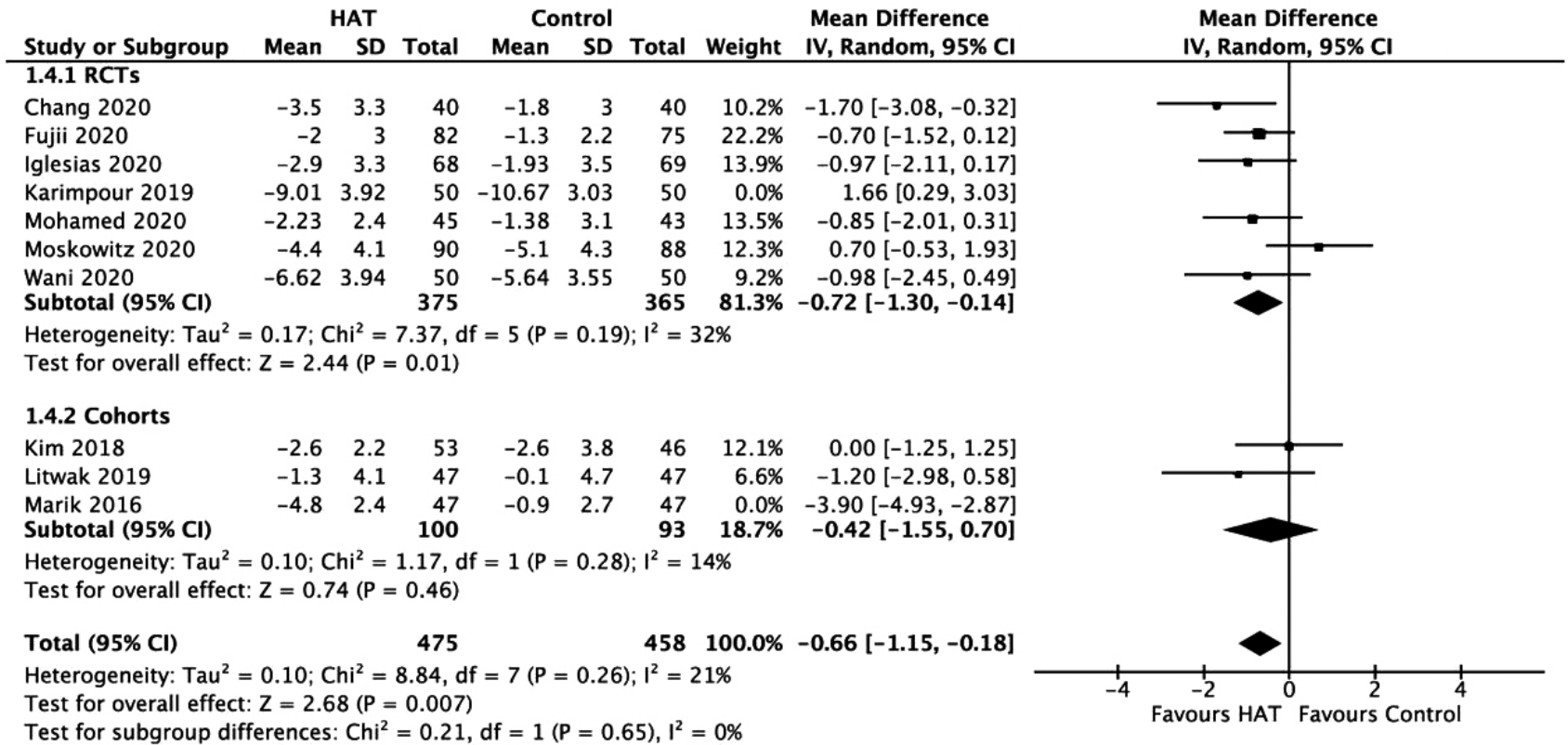

Figure 6. Forest plot showing results of triple therapy from randomized controlled trials (RCTs) and cohort studies on delta Sequential Organ Failure Assessment (SOFA) score without the studies of Karimpour et al. [43] and Marik et al. [39]. HAT: hydrocortisone, ascorbic acid (vitamin C), and thiamine; SD: standard deviation; IV: weighted mean difference; Cl: confidence interval; df: degrees of freedom.

overall effect indicated that the treatment was more favorable (Figure 6).

\section{Hospital Length of Stay}

The results from the RCTs did not show any significant benefit of triple therapy on the hospital LOS (WMD, 0.57; 95\% CI, -1.04 to $\left.2.18 ; \mathrm{P}=0.49 ; \mathrm{I}^{2}=17 \%\right)$. This result is similar to data from retrospective studies (WMD, 3.77; 95\% CI, 0.12-7.41; $\mathrm{P}=0.04$; $\mathrm{I}^{2}=0 \%$ ) (Figure 7 ). 


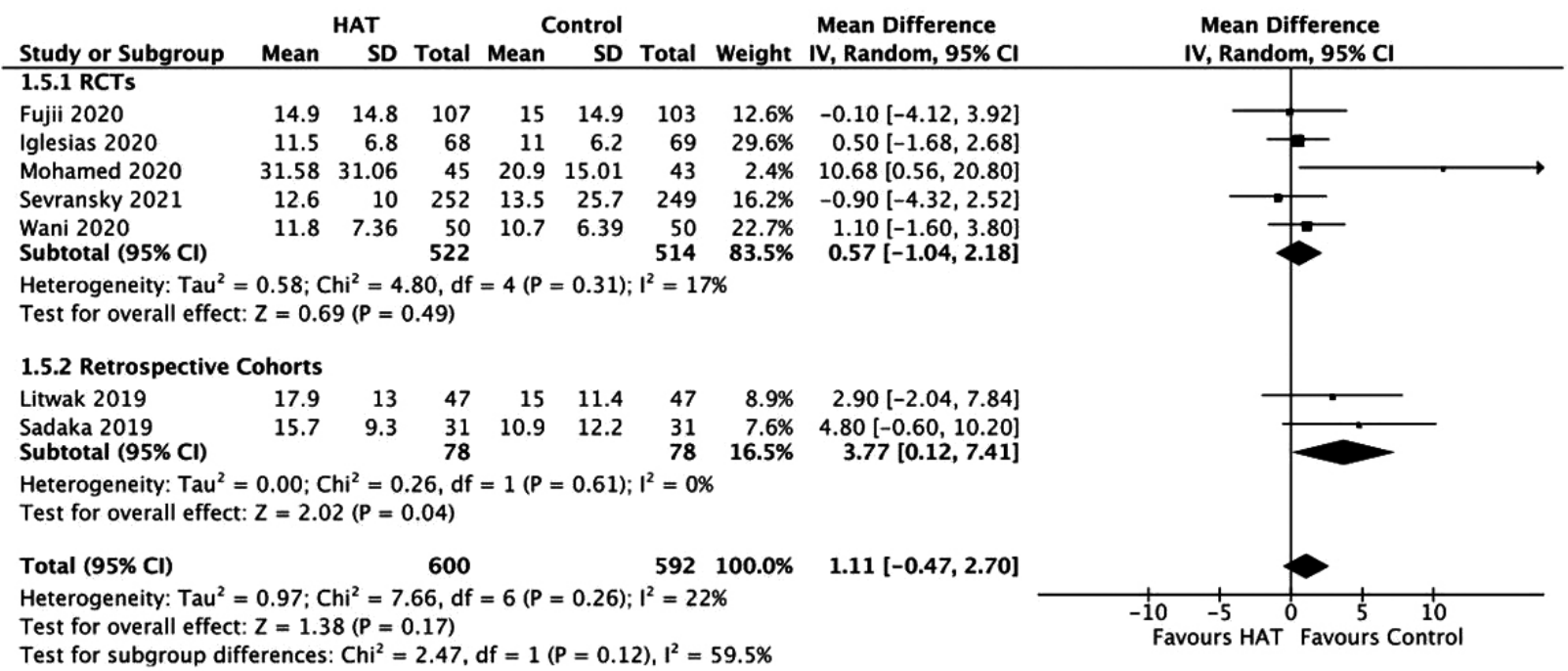

Figure 7. Forest plot showing results of triple therapy from randomized controlled trials (RCTs) and cohort studies on hospital length of stay. HAT: hydrocortisone, ascorbic acid (vitamin C), and thiamine; SD: standard deviation; IV: weighted mean difference; Cl: confidence interval; df: degrees of freedom.

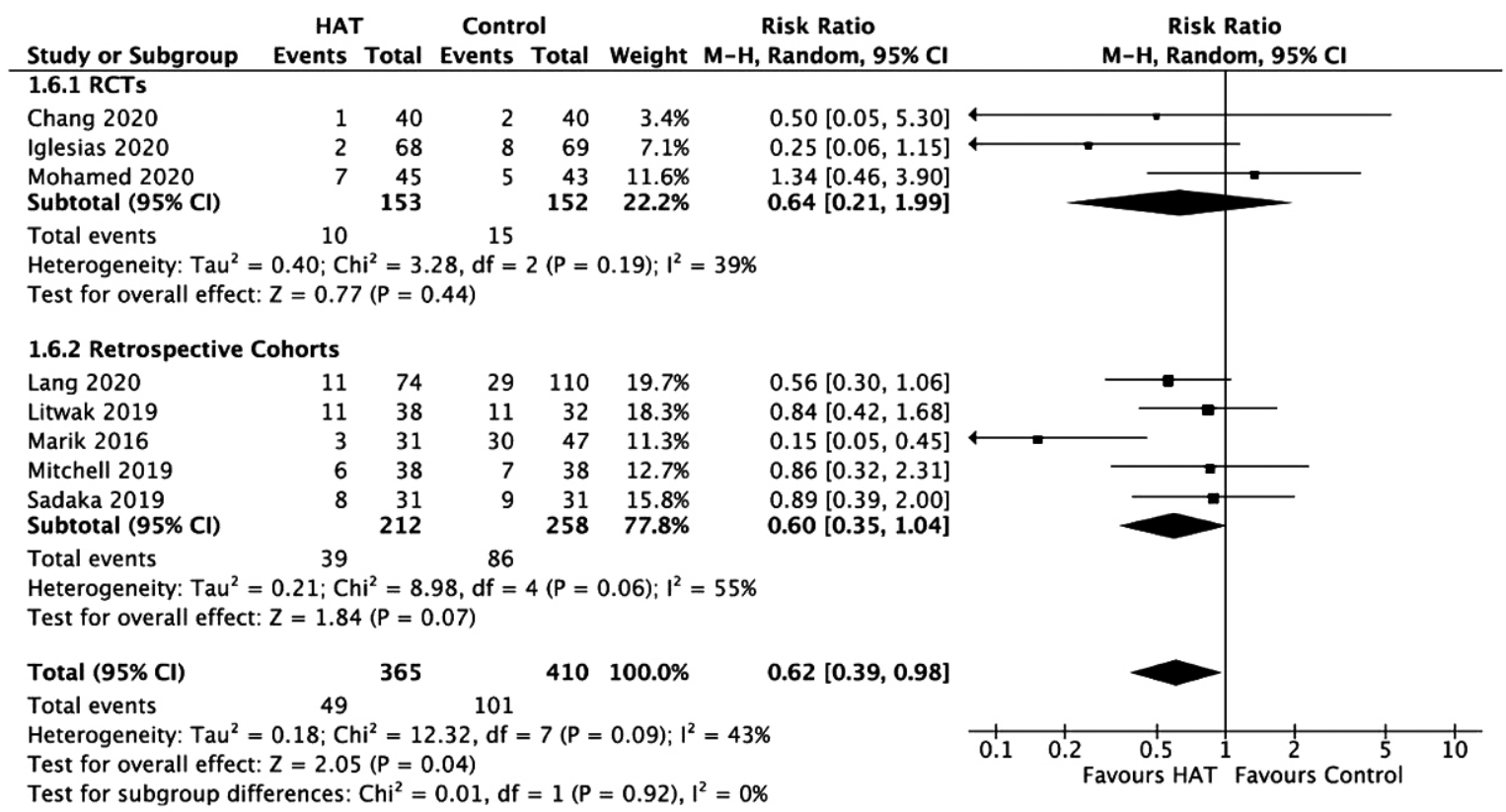

Figure 8. Forest plot showing results of triple therapy from randomized controlled trials (RCTs) and cohort studies on renal replacement therapy. HAT: hydrocortisone, ascorbic acid (vitamin C), and thiamine; Cl: confidence interval; df: degrees of freedom.

\section{Renal Replacement Therapy}

Results from RCTs (RR, 0.64; 95\% CI, 0.21-1.99; P =0.44; $\mathrm{I}^{2}=39 \%$ ) and retrospective cohort studies (RR, 0.60; 95\% CI, 0.35-1.04; $\mathrm{P}=0.07 ; \mathrm{I}^{2}=55 \%$ ) revealed no significant benefit of HAT therapy on RRT (Figure 8). A sensitivity analysis was performed, which showed that the exclusion of the study by Marik et al. [39] made the data homogeneous $\left(\mathrm{I}^{2}=0 \%\right)$; however, there was still no significant benefit of HAT therapy on decreasing the need for RRT.

\section{Duration of Vasopressors}

In Figure 9, the results from RCTs show a significant benefit of HAT therapy on the duration of vasopressor use (WMD, -25.49; 95\% CI, -34.37 to $-16.61, \mathrm{P}<0.00001 ; \mathrm{I}^{2}=46 \%$ ). However, retrospective studies have not reported any benefit (WMD, 20.33; $95 \%$ CI, -56.30 to $\left.-96.96 ; \mathrm{P}=0.60 ; \mathrm{I}^{2}=98 \%, \mathrm{P}<0.00001\right)$. No significant changes were observed upon sensitivity analysis.

Out of seven outcomes, RCTs showed no difference between 

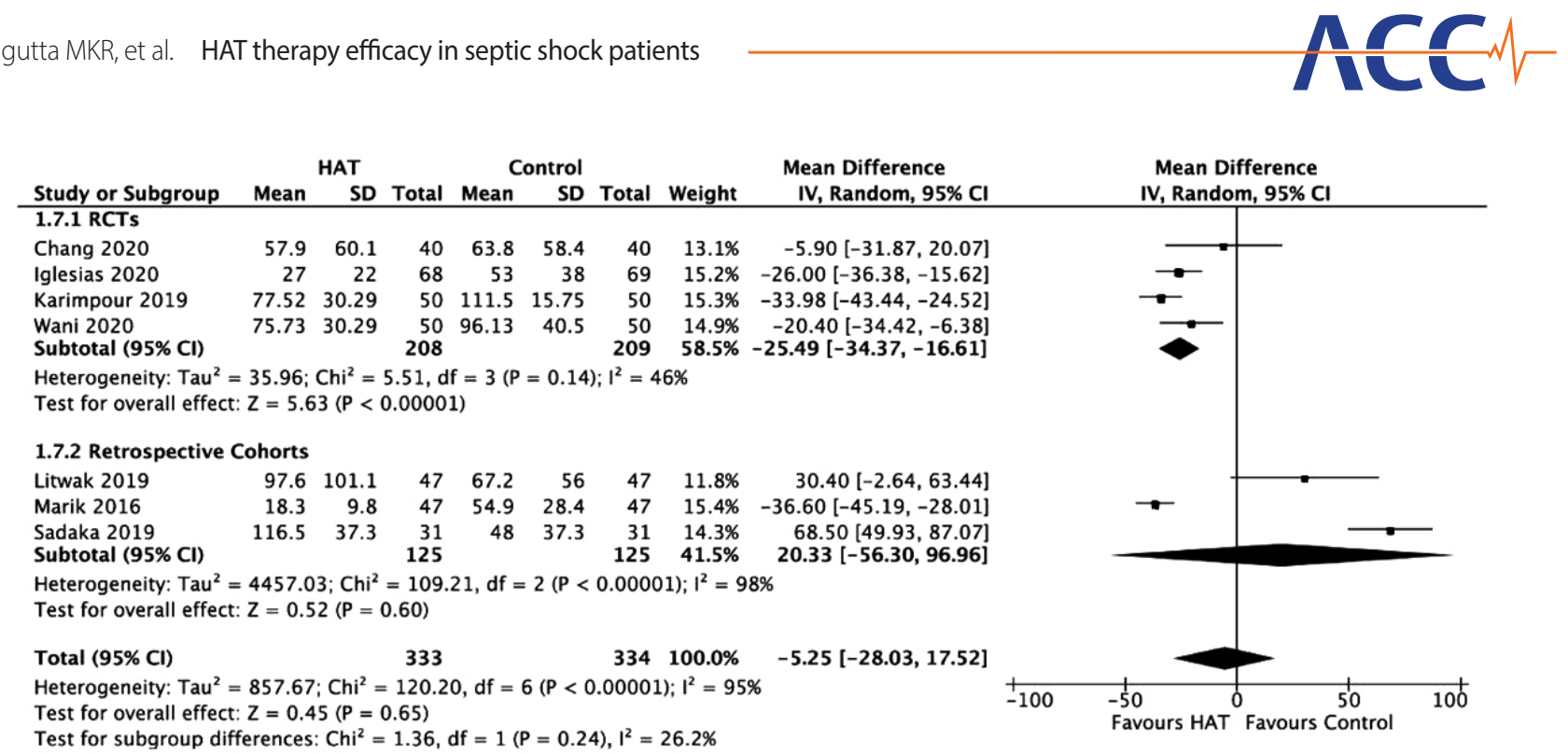

Figure 9. Forest plot showing results of triple therapy from randomized controlled trials (RCTs) and cohort studies on duration of vasopressors. HAT: hydrocortisone, ascorbic acid (vitamin C), and thiamine; SD: standard deviation; IV: weighted mean difference; Cl: confidence interval; df: degrees of freedom.

the triple therapy and the control group regarding hospital mortality, ICU mortality, ICU LOS, hospital LOS, and RRTs. RCTs favored HAT therapy for the delta SOFA score once a sensitivity analysis has been conducted. For the duration of vasopressor use, RCTs favored the use of ascorbic acid, thiamine, and corticosteroids. In the analysis of retrospective cohort studies, there was no benefit of HAT therapy on any of the outcomes. The overall results of both RCTs and retrospective cohorts revealed similar results in which there was no difference between the treatment and control groups in any of the identified outcomes except for the delta SOFA score and the duration of vasopressor use. Further subgroup analysis was performed using the age of patients $<65$ and $\geq 65$ years for studies that showed heterogeneity (Supplementary Figure 2). No significant changes were observed in this analysis.

\section{DISCUSSION}

This systematic review and meta-analysis of 67,349 patients suggests the potential beneficial effects of hydrocortisone, ascorbic acid, and thiamine in patients with sepsis. Multiple studies have proven the beneficial role of micronutrients (including ascorbic acid and thiamine) in maintaining the integrity of vascular and mitochondrial function [16,53,54]. Ascorbic acid is a potent antioxidant that prevents endothelial dysfunction and modulates blood flow, which are clearly affected in sepsis $[7-13,55]$. In one clinical trial, thiamine showed a statistically significance difference at lowering the lactate level compared to the control group and, therefore, possible reduc- tion in overall mortality $[41,42,47,56]$. The combination of thiamine, ascorbic acid, and corticosteroids has been suggested as a potential adjunctive therapy targeted at the non-oxygen delivery-dependent mechanisms of organ dysfunction in sepsis $[41,42,47,56-58]$. Theoretically, based on these substances' mechanisms of action, their combination may have a synergistic effect in treating patients with septic shock. Low levels of thiamine and ascorbic acid in critically ill patients is one rationale for the addition of these medications in such patients $[29,56,58]$. Considering the commonality and high prevalence of sepsis and its attributable morbidity and mortality, it is vital to evaluate the effectiveness of this readily accessible and inexpensive treatment. A previous meta-analysis also reported the overall effect of HAT therapy among sepsis patients, including pediatric populations [56]; however, it did not stratify or analyze the data according to subgroups. Furthermore, our study included evidence from seven additional studies (four RCTs and three cohort studies) that involved only adult patients $[43,45,48-50,52]$, producing a relatively larger sample size and a high methodological quality and thus amplifying the metaanalysis. Despite the adequate number of RCTs in our metaanalysis, we found that the addition of cohort studies would also be beneficial for a more comprehensive analysis.

When comparing our findings to the previous meta-analysis by Shi and Tie [56], the role of combination therapy was determined to have no effect on the mortality and overall survival rate among RCTs. However, a significant reduction in the mortality rate was observed for pooled cohort studies in the study of Shi and Tie [56], which was not observed in our meta- 
analysis. A retrospective study conducted by Marik et al. [39] reported that patients who received HAT therapy had a hospital mortality of $8.5 \%$ compared to the $40.4 \%$ hospital mortality seen in the control arm. Sevransky et al. [52] showed a day-30 mortality rate of $22.2 \%$ in the treatment group and $24.8 \%$ in the control arm (RR, 0.92; 95\% CI, 0.67-1.27). Fujii et al. [42] reported similar results (23.4\% vs. $20.4 \%)$ with an RR of 1.15 (95\% CI, 0.69-1.91). In addition, Wani et al. [44] demonstrated a $24 \%$ hospital mortality in patients receiving HAT therapy compared to $28 \%$ in controls with an RR of 0.86 (95\% CI, 0.44-1.66). The overall estimate in our study has shown no significant benefit of HAT therapy on hospital mortality in RCTs and cohort studies. The ICU mortality has not been analyzed as an outcome in previous meta-analyses, and our results showed no significant benefit on ICU mortality with HAT therapy, unlike the Vitamin C, Thiamine, and Steroids in Sepsis (VICTAS) trial, which concluded a lower death likelihood ratio that favored the HAT group (RR, 0.55; 95\% CI, 0.41-0.73) [52].

Despite the additional RCTs included in our analysis, the number of patients may still be inadequate to reflect a benefit in mortality rate. The difference in the results of the Shi and Tie's study [56] may be due to different inclusion criteria among the cohort studies. For example, in the study of Marik et al. [39], a procalcitonin level of $>2 \mathrm{ng} / \mathrm{ml}$ was part of the inclusion criteria; the study of Kim et al. [45] only included ICU patients with severe pneumonia, while the study of Vail et al. [48] analyzed the records of all patients with ICD-10 codes for infection and organ dysfunction [39]. Hence, we cannot provide a definitive conclusion regarding the effect of HAT on mortality in septic patients.

Conflicting results were observed for the delta SOFA score. Initially in our study, no significant improvement was noted in the SOFA score; however, after a sensitivity analysis, RCTs favored the treatment group. The results from the study of Moskowitz et al. [47] revealed that HAT therapy did not produce a change in the SOFA score after 72 hours. However, in the Shi and Tie meta-analysis [56], there was a clear benefit of HAT therapy in both RCTs and cohort studies on the SOFA score.

The pooled results from our RCTs indicated that HAT therapy significantly decreased the duration of vasopressor use in septic patients. These results are in agreement with the findings of Shi and Tie [56]. Ascorbic acid plays a role in the increased production of endogenous catecholamines, leading to improved microvascular function in septic patients $[9,16,29,47]$. Thiamine aids in the aerobic metabolism of cells and may improve microvascular function and prevent organ failure [47,
$16,29,59]$. In contrast, hydrocortisone may play a role in the potentiation of catecholamines, the mitigation of inflammation, and the prevention of vascular smooth muscle relaxation [45]. The results of this meta-analysis further support this theory by demonstrating a reduced duration of vasopressor use with HAT therapy in sepsis patients. Despite promising results for this outcome, HAT therapy did not significantly benefit mortality, the ICU or hospital LOS, or the RRT.

A subgroup analysis was conducted based on patient age. Aging has a significant influence on the survival rate, mortality rate, and recovery rate of sepsis. Age is an independent risk factor for mortality because the immune system and body responses decrease with age, making patients more susceptible to infection and pathogens as they age. As a result, more than $60 \%$ of patients diagnosed with sepsis are $>65$ years of age $[41,42]$. Martin et al. [60] found an increase in the incidence across all adult patients with a case fatality rate tenfold higher in people aged $\geq 65$ years compared with populations $<65$. Starr and Saito [61] concluded that older survivors would likely suffer from long-term dysfunction and higher mortality rates even after being discharged home. The effect of treatment on outcomes had no difference in the two age groups $(\geq 65,<65$ years). For example, there was no significant change in the survival outcome between the younger participants in Sevransky et al.'s clinical trial [52] and in other studies with a mean age > 65 years (RR, 0.95; 95\% CI, 0.64-1.43; $\mathrm{P}=0.81 ; \mathrm{I}^{2}=74 \%$ ). The same effect in ICU mortality was also seen for elderly people as an RR of 0.59 (95\% CI, 0.26-1.36; $\left.\mathrm{P}=0.22 ; \mathrm{I}^{2}=65 \%\right)$.

There are several strengths of our meta-analysis. To the best of our knowledge, this is the most comprehensive description of the outcome of triple therapy with hydrocortisone, ascorbic acid, and thiamine in sepsis patients, including outcomes such as the hospital and ICU mortality and LOS, the delta SOFA score, the need for RRT, and the duration of vasopressor use. A systematic search of the literature using predefined inclusion and exclusion criteria has allowed precise extraction to assess publication bias, subgroup analysis, and accurate data outcomes.

This study should be viewed in light of a few limitations. The included studies were relatively uniform in terms of their doses of medications and the frequency and duration of treatment. However, the results were subject to considerable heterogeneity, which was possibly due to variations in the study designs, sample sizes, settings, and patient baseline characteristics. In addition, other clinical variations, such as the timing of HAT and the severity of the disease, should also be considered. We attempted to mitigate the limitation of heterogeneity by per- 
forming a subgroup analysis. However, limited data only allowed us to use age as a subgroup. The sample size of most RCTs was small. The study by Sevransky et al. [52] was terminated early due to administrative reasons, which may have affected the study's ability to interpret long-term outcomes. Additionally, pooled effects between RCTs and cohort studies on outcomes were variable (the delta SOFA score and the duration of vasopressor use). For the other outcomes measured, cohort studies generally supported the findings of RCTs (hospital and ICU mortality, ICU and hospital LOS, and RRT).

To further mitigate the ongoing debate about using HAT therapy in sepsis patients, we consolidated outcomes from all available studies. A pooled analysis of the RCTs suggested that HAT therapy significantly reduced the duration of vasopressor use and improved the SOFA score, whereas it appeared not to have significant benefits in other outcomes for patients with sepsis. However, large-scale RCTs are still required before a definite conclusion can be drawn, especially regarding treatment dosage and timing.

\section{CONFLICT OF INTEREST}

No potential conflict of interest relevant to this article was reported.

\section{ORCID}

Manoj Kumar Reddy Somagutta https://orcid.org/0000-0002-6502-2169

Maria Kezia Lourdes Pormento https://orcid.org/0000-0003-2088-6243

Muhammad Adnan Khan https://orcid.org/0000-0003-1934-7998

Alaa Hamdan https://orcid.org/0000-0002-0972-2830

Namrata Hange https://orcid.org/0000-0002-2005-0692

Manish KC https://orcid.org/0000-0003-1693-6068

Sukrut Pagad https://orcid.org/0000-0003-4256-8430

Molly Sanjay Jain https://orcid.org/0000-0001-6783-6476 Sivasthikka Lingarajah

https://orcid.org/0000-0002-9484-8808

Vishal Sharma $\quad$ https://orcid.org/0000-0001-7283-5734 Jaspreet Kaur https://orcid.org/0000-0002-5224-5814 Bernard Emuze https://orcid.org/0000-0002-1907-3168 Erkan Batti https://orcid.org/0000-0001-7828-7927 Obumneme Jude Iloeje

https://orcid.org/0000-0001-9055-8363

\section{AUTHOR CONTRIBUTIONS}

Conceptualization: MKRS, MKLP, MAK, AH, NH, MKC, SP. Data curation: MKRS, MKLP, MAK, AH, NH, MKC, SP, MSJ, SL, VS, JK, BE, EB. Formal analysis: MKRS, MKLP, MAK, AH, NH, MKC, SP. Methodology: MAK, MKRS, AH, NH, MKC, SP. Project administration: MKRS, MKLP, MSJ, OJI. Visualization: MKRS, MSJ, SL, VS, JK, BE, EB. Writing-original draft: MKRS, MKLP, MAK, AH, NH, MKC, SP, MSJ, SL, VS, JK, BE, EB. Writing-review \& editing: all authors.

\section{SUPPLEMENTARY MATERIALS}

Supplementary materials can be found via https://doi.org/ 10.4266/acc.2021.00108.

\section{REFERENCES}

1. Abraham E. New definitions for sepsis and septic shock: continuing evolution but with much still to be done. JAMA 2016; 315:757-9

2. Angus DC, van der Poll T. Severe sepsis and septic shock. N Engl J Med 2013;369:840-51.

3. Beesley SJ, Lanspa MJ. Why we need a new definition of sepsis. Ann Transl Med 2015;3:296.

4. Allegranzi B, Bagheri Nejad S, Chraiti MN, Castillejos GG, Kilpatrick C, Kelley E. Report on the burden of endemic health care-associated infection worldwide. Geneva: World Health Organization; 2011.

5. Rudd KE, Johnson SC, Agesa KM, Shackelford KA, Tsoi D, Kievlan DR, et al. Global, regional, and national sepsis incidence and mortality, 1990-2017: analysis for the Global Burden of Disease Study. Lancet 2020;395:200-11.

6. Marik PE, Farkas JD. The changing paradigm of sepsis: early diagnosis, early antibiotics, early pressors, and early adjuvant treatment. Crit Care Med 2018;46:1690-2.

7. Galley HF, Howdle PD, Walker BE, Webster NR. The effects of intravenous antioxidants in patients with septic shock. Free Radic Biol Med 1997;23:768-74.

8. Wilson JX. Mechanism of action of vitamin C in sepsis: ascorbate modulates redox signaling in endothelium. Biofactors 2009;35:5-13.

9. Kuhn SO, Meissner K, Mayes LM, Bartels K. Vitamin C in sepsis. Curr Opin Anaesthesiol 2018;31:55-60.

10. Mandl J, Szarka A, Bánhegyi G. Vitamin C: update on physiology and pharmacology. Br J Pharmacol 2009;157:1097-110.

11. Heo HJ, Lee CY. Protective effects of quercetin and vitamin C 
against oxidative stress-induced neurodegeneration. J Agric Food Chem 2004;52:7514-7.

12. May JM, Harrison FE. Role of vitamin $C$ in the function of the vascular endothelium. Antioxid Redox Signal 2013;19:206883.

13. Zhou G, Kamenos G, Pendem S, Wilson JX, Wu F. Ascorbate protects against vascular leakage in cecal ligation and puncture-induced septic peritonitis. Am J Physiol Regul Integr Comp Physiol 2012;302:R409-16.

14. Costa NA, Azevedo PS, Polegato BF, Zornoff LA, Paiva SA, Minicucci MF. Thiamine as a metabolic resuscitator in septic shock: one size does not fit all. J Thorac Dis 2016;8:E471-2.

15. Moskowitz A, Donnino MW. Thiamine (vitamin B1) in septic shock: a targeted therapy. J Thorac Dis 2020;12(Suppl 1):S7883.

16. Donnino MW, Andersen LW, Chase M, Berg KM, Tidswell M, Giberson T, et al. Randomized, double-blind, placebo-controlled trial of thiamine as a metabolic resuscitator in septic shock: a pilot study. Crit Care Med 2016;44:360-7.

17. Costa NA, Gut AL, de Souza Dorna M, Pimentel JA, Cozzolino SM, Azevedo PS, et al. Serum thiamine concentration and oxidative stress as predictors of mortality in patients with septic shock. J Crit Care 2014;29:249-52.

18. Woolum JA, Abner EL, Kelly A, Thompson Bastin ML, Morris $\mathrm{PE}$, Flannery AH. Effect of thiamine administration on lactate clearance and mortality in patients with septic shock. Crit Care Med 2018;46:1747-52.

19. Artigas A, Carlet J, Garnacho J, Niederman M, Torres A. 24th international symposium on infections in the critically ill patient. Med Sci 2019;7:23.

20. Erstad BL, Brophy GM, Martin SJ, Haas CE, Devlin JW, Welage LS, et al. Key articles and guidelines relative to intensive care unit pharmacotherapy: 2009 update. Pharmacotherapy 2009; 29:1228-69.

21. Annane D. The role of ACTH and corticosteroids for sepsis and septic shock: an update. Front Endocrinol (Lausanne) 2016;7:70.

22. Schumer W. Steroids in the treatment of clinical septic shock. Ann Surg 1976;184:333-41.

23. Keh D, Trips E, Marx G, Wirtz SP, Abduljawwad E, Bercker S, et al. Effect of hydrocortisone on development of shock among patients with severe sepsis: the HYPRESS randomized clinical trial. JAMA 2016;316:1775-85.

24. Marik PE, Pastores SM, Annane D, Meduri GU, Sprung CL, Arlt W, et al. Recommendations for the diagnosis and management of corticosteroid insufficiency in critically ill adult patients: consensus statements from an international task force by the American College of Critical Care Medicine. Crit Care Med 2008;36:1937-49.

25. Annane D, Sébille V, Charpentier C, Bollaert PE, François B, Korach JM, et al. Effect of treatment with low doses of hydrocortisone and fludrocortisone on mortality in patients with septic shock. JAMA 2002;288:862-71.

26. Sprung CL, Annane D, Keh D, Moreno R, Singer M, Freivogel $\mathrm{K}$, et al. Hydrocortisone therapy for patients with septic shock. N Engl J Med 2008;358:111-24.

27. Keh D, Boehnke T, Weber-Cartens S, Schulz C, Ahlers O, Bercker S, et al. Immunologic and hemodynamic effects of "lowdose" hydrocortisone in septic shock: a double-blind, randomized, placebo-controlled, crossover study. Am J Respir Crit Care Med 2003;167:512-20.

28. Moskowitz A, Andersen LW, Huang DT, Berg KM, Grossestreuer AV, Marik PE, et al. Ascorbic acid, corticosteroids, and thiamine in sepsis: a review of the biologic rationale and the present state of clinical evaluation. Crit Care 2018;22:283.

29. Marik PE. Hydrocortisone, ascorbic acid and thiamine (HAT therapy) for the treatment of sepsis: focus on ascorbic acid. Nutrients 2018;10:1762.

30. Singer M, Deutschman CS, Seymour CW, Shankar-Hari M, Annane D, Bauer M, et al. The third international consensus definitions for sepsis and septic shock (Sepsis-3). JAMA 2016; 315:801-10.

31. Stang A. Critical evaluation of the Newcastle-Ottawa scale for the assessment of the quality of nonrandomized studies in meta-analyses. Eur J Epidemiol 2010;25:603-5.

32. Wells GA, Shea B, O'Connell D, Peterson J, Welch V, Losos M, et al. The Newcastle-Ottawa Scale (NOS) for assessing the quality of nonrandomised studies in meta-analyses. Ottawa: Ottawa Hospital Research Institute; 2000.

33. Luo D, Wan X, Liu J, Tong T. Optimally estimating the sample mean from the sample size, median, mid-range, and/or midquartile range. Stat Methods Med Res 2018;27:1785-805.

34. Wan X, Wang W, Liu J, Tong T. Estimating the sample mean and standard deviation from the sample size, median, range and/or interquartile range. BMC Med Res Methodol 2014;14: 135.

35. Patsopoulos NA, Evangelou E, Ioannidis JP. Sensitivity of between-study heterogeneity in meta-analysis: proposed metrics and empirical evaluation. Int J Epidemiol 2008;37:114857.

36. DerSimonian R, Laird N. Meta-analysis in clinical trials. Control Clin Trials 1986;7:177-88.

37. Mathes T, Kuss O. A comparison of methods for meta-analysis of a small number of studies with binary outcomes. Res 
Synth Methods 2018;9:366-81.

38. Sadaka F, Grady J, Organti N, Donepudi B, Korobey M, Tannehill D, et al. Ascorbic acid, thiamine, and steroids in septic shock: propensity matched analysis. J Intensive Care Med 2020;35:1302-6.

39. Marik PE, Khangoora V, Rivera R, Hooper MH, Catravas J. Hydrocortisone, vitamin $\mathrm{C}$, and thiamine for the treatment of severe sepsis and septic shock: a retrospective before-after study. Chest 2017;151:1229-38.

40. Mitchell AB, Ryan TE, Gillion AR, Wells LD, Muthiah MP. Vitamin $\mathrm{C}$ and thiamine for sepsis and septic shock. Am J Med 2020;133:635-8.

41. Litwak JJ, Cho N, Nguyen HB, Moussavi K, Bushell T. Vitamin $\mathrm{C}$, hydrocortisone, and thiamine for the treatment of severe sepsis and septic shock: a retrospective analysis of real-world application. J Clin Med 2019;8:478.

42. Fujii T, Luethi N, Young PJ, Frei DR, Eastwood GM, French CJ, et al. Effect of vitamin C, hydrocortisone, and thiamine vs hydrocortisone alone on time alive and free of vasopressor support among patients with septic shock: the VITAMINS randomized clinical trial. JAMA 2020;323:423-31.

43. Karimpour H, Bahrami A, Amini S, Rezaei M, Amini-Saman J, Shahbazi F. Effects of a high dose of vitamin $C$ along with thiamine in critically-ill patients with septic shock: a preliminary study. J Pharm Res Int 2019;29:1-7.

44. Wani SJ, Mufti SA, Jan RA, Shah SU, Qadri SM, Khan UH, et al. Combination of vitamin $\mathrm{C}$, thiamine and hydrocortisone added to standard treatment in the management of sepsis: results from an open label randomized controlled clinical trial and a review of the literature. Infect Dis (Lond) 2020;52:271-8.

45. Kim WY, Jo EJ, Eom JS, Mok J, Kim MH, Kim KU, et al. Combined vitamin $\mathrm{C}$, hydrocortisone, and thiamine therapy for patients with severe pneumonia who were admitted to the intensive care unit: propensity score-based analysis of a before-after cohort study. J Crit Care 2018;47:211-18.

46. Iglesias J, Vassallo AV, Patel VV, Sullivan JB, Cavanaugh J, Elbaga Y. Outcomes of metabolic resuscitation using ascorbic acid, thiamine, and glucocorticoids in the early treatment of sepsis: the ORANGES trial. Chest 2020;158:164-73.

47. Moskowitz A, Huang DT, Hou PC, Gong J, Doshi PB, Grossestreuer AV, et al. Effect of ascorbic acid, corticosteroids, and thiamine on organ injury in septic shock: the ACTS randomized clinical trial. JAMA 2020;324:642-50.

48. Vail EA, Wunsch H, Pinto R, Bosch NA, Walkey AJ, Lindenauer PK, et al. Use of hydrocortisone, ascorbic acid, and thiamine in adults with septic shock. Am J Respir Crit Care Med 2020;202:1531-9.
49. Mohamed ZU, Prasannan P, Moni M, Edathadathil F, Prasanna $\mathrm{P}$, Menon A, et al. Vitamin C therapy for routine care in septic shock (ViCTOR) trial: effect of intravenous vitamin $\mathrm{C}$, thiamine, and hydrocortisone administration on inpatient mortality among patients with septic shock. Indian J Crit Care Med 2020;24:653-61.

50. Long MT, Frommelt MA, Ries MP, Murray M, Osman F, Krause $\mathrm{BM}$, et al. Early hydrocortisone, ascorbate and thiamine therapy for severe septic shock. Crit Care Shock 2020;23:23-34.

51. Chang P, Liao Y, Guan J, Guo Y, Zhao M, Hu J, et al. Combined treatment with hydrocortisone, vitamin $\mathrm{C}$, and thiamine for sepsis and septic shock: a randomized controlled trial. Chest 2020;158:174-82.

52. Sevransky JE, Rothman RE, Hager DN, Bernard GR, Brown SM, Buchman TG, et al. Effect of vitamin C, thiamine, and hydrocortisone on ventilator- and vasopressor-free days in patients with sepsis: the VICTAS randomized clinical trial. JAMA 2021;325:742-50

53. Barabutis N, Khangoora V, Marik PE, Catravas JD. Hydrocortisone and ascorbic acid synergistically prevent and repair lipopolysaccharide-induced pulmonary endothelial barrier dysfunction. Chest 2017;152:954-62.

54. Berger MM. Do micronutrient deficiencies contribute to mitochondrial failure in critical illness? Curr Opin Clin Nutr Metab Care 2020;23:102-10.

55. Hwang SY, Ryoo SM, Park JE, Jo YH, Jang DH, Suh GJ, et al. Combination therapy of vitamin $\mathrm{C}$ and thiamine for septic shock: a multi-centre, double-blinded randomized, controlled study. Intensive Care Med 2020;46:2015-25.

56. Shi $\mathrm{R}$, Tie H. Benefit of hydrocortisone, thiamine, and vitamin C for patients with sepsis or septic shock? Too early to draw conclusions. Crit Care 2020;24:431.

57. Rowe TA, McKoy JM. Sepsis in older adults. Infect Dis Clin North Am 2017;31:731-42.

58. Kim J, Arnaout L, Remick D. Hydrocortisone, ascorbic acid, and thiamine (HAT) therapy decreases oxidative stress, improves cardiovascular function, and improves survival in murine sepsis. Shock 2020;53:460-7.

59. Petsakul S, Morakul S, Tangsujaritvijit V, Kunawut P, Singhatas $\mathrm{P}$, Sanguanwit P. Effects of thiamine on vasopressor requirements in patients with septic shock: a prospective randomized controlled trial. BMC Anesthesiol 2020;20:280

60. Martin GS, Mannino DM, Moss M. The effect of age on the development and outcome of adult sepsis. Crit Care Med 2006 34:15-21.

61. Starr ME, Saito H. Sepsis in old age: review of human and animal studies. Aging Dis 2014;5:126-36. 
Supplementary Table 1. Risk of bias assessment of retrospective cohorts

\begin{tabular}{|c|c|c|c|c|c|c|c|c|c|c|}
\hline \multirow[b]{2}{*}{ Study } & \multicolumn{4}{|c|}{ Selection } & \multicolumn{2}{|c|}{ Comparability } & \multicolumn{3}{|c|}{ Outcome } & \multirow[b]{2}{*}{ Total } \\
\hline & $\begin{array}{c}\text { Exposed } \\
\text { cohort }\end{array}$ & $\begin{array}{l}\text { Non- } \\
\text { exposed } \\
\text { cohort }\end{array}$ & $\begin{array}{l}\text { Ascertain- } \\
\text { ment of } \\
\text { exposure }\end{array}$ & $\begin{array}{l}\text { Demon- } \\
\text { stration } \\
\text { outcome }\end{array}$ & $\begin{array}{l}\text { Basic } \\
\text { factor }\end{array}$ & $\begin{array}{l}\text { Additional } \\
\text { factor }\end{array}$ & $\begin{array}{c}\text { Assess- } \\
\text { ment }\end{array}$ & Follow-up & Adequacy & \\
\hline Marik (2016) [39] & 1 & 1 & 1 & 1 & 1 & 0 & 1 & 1 & 1 & 8 \\
\hline $\operatorname{Kim}(2018)$ [45] & 0 & 1 & 1 & 1 & 1 & 0 & 1 & 1 & 1 & 7 \\
\hline Mitchell (2019) [40] & 1 & 1 & 1 & 1 & 1 & 0 & 1 & 1 & 0 & 7 \\
\hline Litwak (2019) [41] & 1 & 1 & 1 & 1 & 1 & 0 & 1 & 1 & 1 & 8 \\
\hline Sadaka (2019) [38] & 0 & 1 & 1 & 1 & 1 & 1 & 1 & 0 & 1 & 7 \\
\hline Vail (2020) [48] & 0 & 1 & 1 & 1 & 1 & 1 & 1 & 1 & 1 & 8 \\
\hline Long (2020) [50] & 1 & 1 & 1 & 1 & 1 & 0 & 1 & 1 & 1 & 7 \\
\hline
\end{tabular}


Supplementary Table 2. Risk of bias assessment of RCTs

\begin{tabular}{|c|c|c|c|c|c|c|}
\hline Study & $\begin{array}{c}\text { Randomization } \\
\text { process }\end{array}$ & $\begin{array}{l}\text { Deviation from in- } \\
\text { tended intervention }\end{array}$ & $\begin{array}{l}\text { Missing outcome } \\
\text { data }\end{array}$ & $\begin{array}{l}\text { Measurement } \\
\text { of outcome }\end{array}$ & $\begin{array}{l}\text { Selection of } \\
\text { reported results }\end{array}$ & $\begin{array}{c}\text { Overall risk } \\
\text { of bias }\end{array}$ \\
\hline Fujii (2020) [42] & Low & Some concerns & Low & Low & Low & Some concerns \\
\hline Karimpour (2020) [43] & Low & Low & Low & Low & Some concerns & Some concerns \\
\hline Wani (2020) [44] & Some concern & Low & Low & Low & Some concerns & Some concerns \\
\hline Iglesias (2020) [46] & Low & Low & Low & Low & Low & Low \\
\hline Moskowitz (2020) [47] & Low & Low & Low & Low & Low & Low \\
\hline Mohamed (2020) [49] & Low & Some concerns & Low & Low & Low & Some concerns \\
\hline Chang (2020) [51] & Low & Some concerns & Low & Low & Low & Some concerns \\
\hline Sevransky (2021)[52] & Low & Low & Low & Low & Low & Low \\
\hline
\end{tabular}

RCT: randomized controlled trial. 

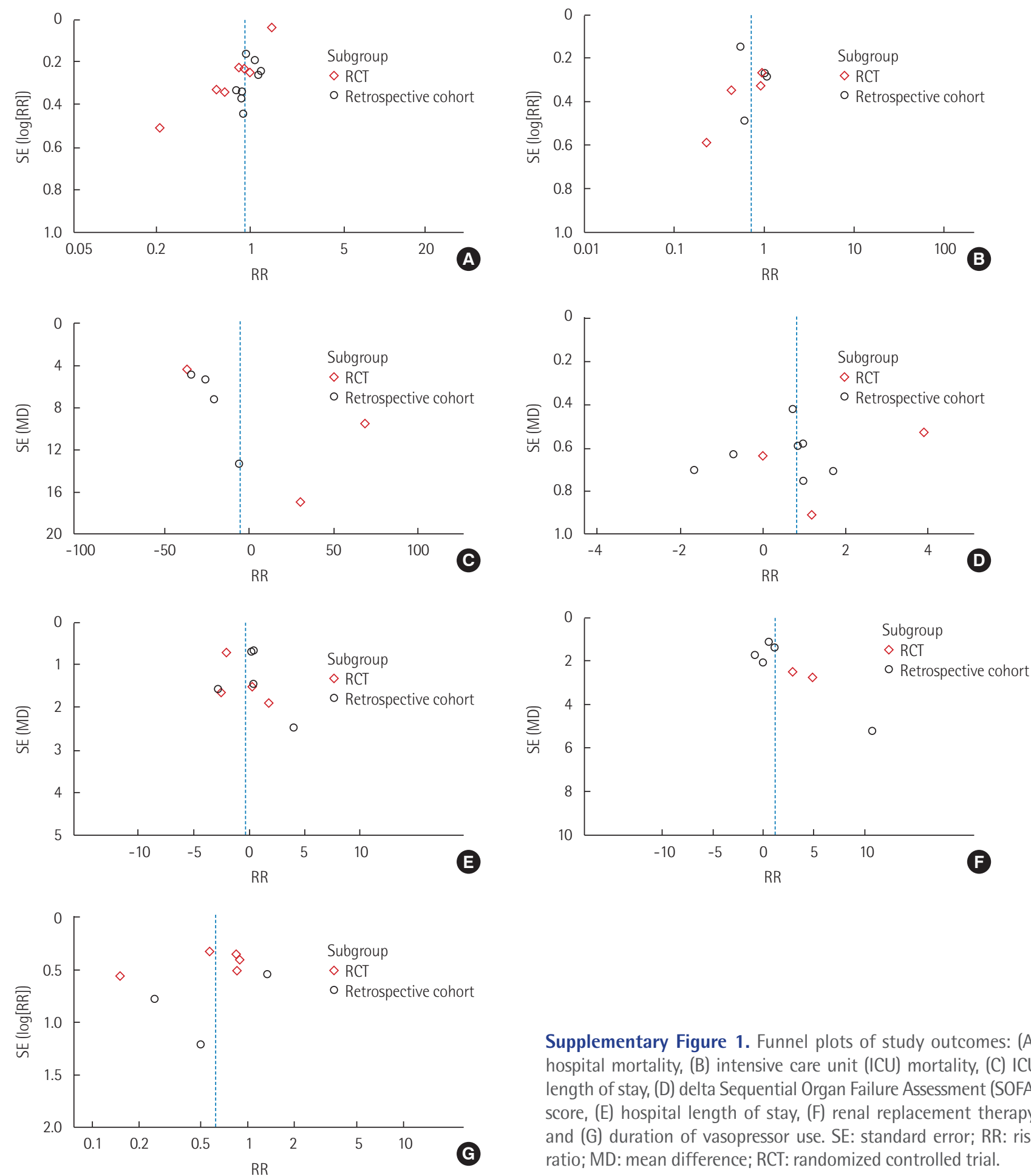

Supplementary Figure 1. Funnel plots of study outcomes: (A) hospital mortality, (B) intensive care unit (ICU) mortality, (C) ICU length of stay, (D) delta Sequential Organ Failure Assessment (SOFA) score, (E) hospital length of stay, (F) renal replacement therapy, and $(\mathrm{G})$ duration of vasopressor use. SE: standard error; RR: risk ratio; MD: mean difference; RCT: randomized controlled trial. 

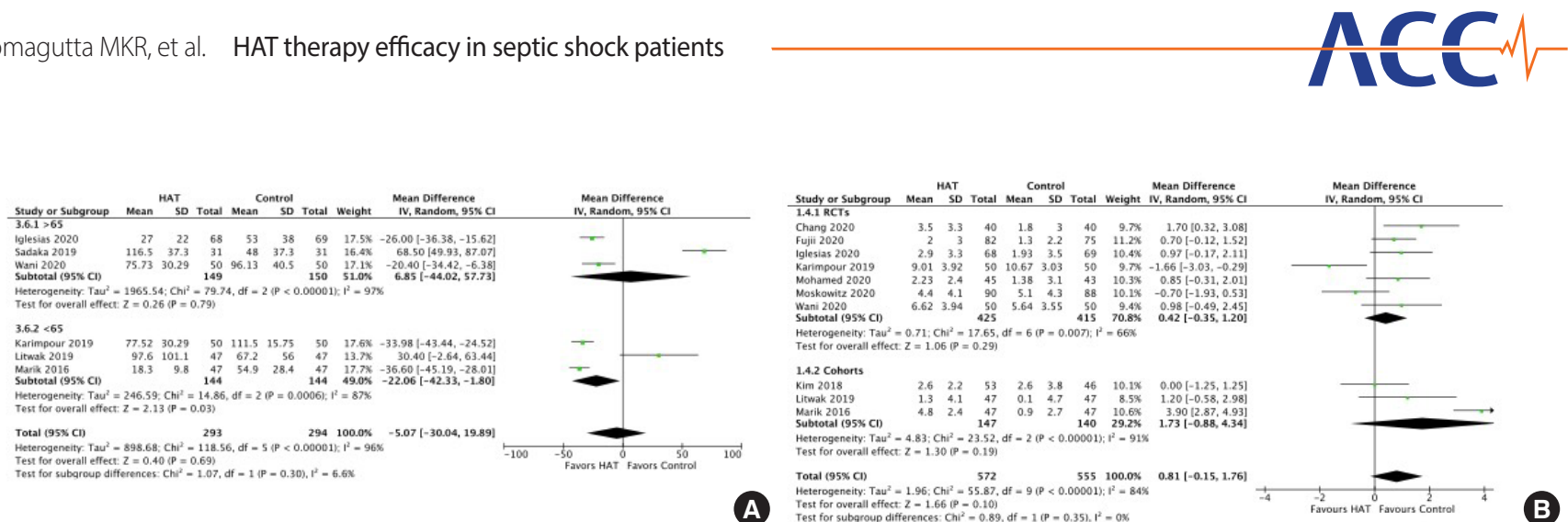

B
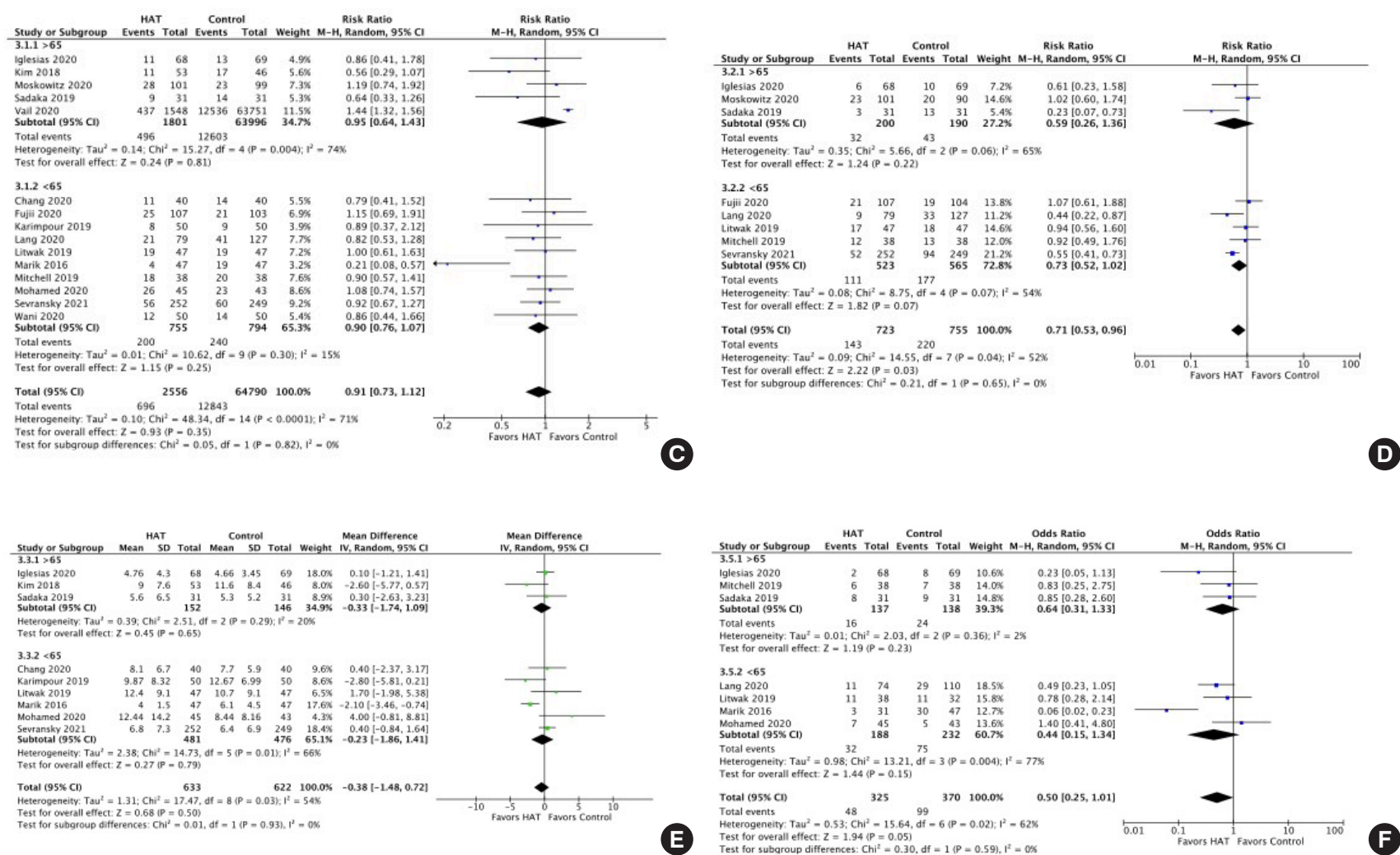

Supplementary Figure 2. Forest plots of subgroup analysis based on age for the study outcomes: (A) duration of vasopressor use, (B) delta Sequential Organ Failure Assessment (SOFA) score, (C) hospital mortality, (D) intensive care unit (ICU) mortality, (E) ICU length of stay, and (F) renal replacement therapy. HAT: hydrocortisone, ascorbic acid (vitamin C), and thiamine; SD: standard deviation; IV: weighted mean difference; $\mathrm{Cl}$ : confidence interval; df: degrees of freedom. 